\title{
GIS application for the evaluation of accessibility indicators of the road network between two hospitals: Case study - Tlemcen City (Algeria)
}

\author{
Sofiane Bounaceur ${ }^{* 1}$, Ahmed Boumediene ${ }^{1}$, Hocine Nechniche', \\ Ghouti Abdellaoui' \\ ${ }^{1}$ Université des Sciences et de la Technologie d'Oran Mohamed Boudiaf, Algérie \\ ${ }^{2}$ Université Abou-Bakr Belkaid, Algérie
}

The notion of mobility within the geographical space was founded on the decisions and activities of humans, whether in their daily life or certain specific professions (railway stations, airports, hospitals). The state of the transport structure networks and the efficiency and quality of their functioning create a spatial heterogeneity which results in more or less uncomfortable access conditions for the movement between two locations, thus affecting travel time. Measurements obtained through complete microscopic simulations determine any increase in value in travel time, which in turn makes it possible to predict network performance within congestion situation (functional vulnerability). In this paper, the authors suggest a GIS method in under to evaluate the intrinsic degrees of vulnerability based on travel time in the road network of Tlemcen city (Algeria) as well as on the structural and functional state of the road network and the way length in order to optimize the travel time required for a hospital emergency service. This may reduce casualities, all too often caused by choosing an inappropriate route.

Key Words: GIS, road network, vulnerability, accessibility, Shortest Time Path (STP).

Article Info: Received: February 14, 2019; Revised: October 30, 2019; Accepted: November 10, 2019; Online: November 30, 2019.

\footnotetext{
* Corresponding author

Address: Université des Sciences et de la Technologie d'Oran Mohamed Boudiaf, USTO-MB, BP 1505, El M'naouer, 31000 Oran Algérie

Phone: +213555928459 | Email: sofiane.bounaceur@univ-usto.dz
}

(C)2019 Human Geographies; The authors

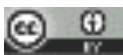

This work is licensed under a

Creative Commons Attribution 4.0 International License. DOI:10.5719/hgeo.2019.132.3 


\section{Introduction}

The relevant question to be raised is: how to identify the best possible routes in a road network, as it is vast and diverse. Accessibility in the context of transportation planning is the ability of people to reach destinations. Different approaches can be used in this context according to different methods based on specific criteria, with accessibility measured based on gravity (journey time) being the most important. Decision-making tools are needed to enable planners and policymakers to better assess this accessibility indicator through careful planning and the development of better road infrastructure to minimise broader impacts on business economy; employment, trade and social activities at large in cities and outskirts (Curl et al., 2011).

The management of a transport network has a direct influence on the quality of services, especially in critical conditions like the one that will be dealt with in the present study (the road selection for Emergency Transport Services between hospitals). Studies conducted by Agence Nationale d'Autoroute (2017) revealed that $35 \%$ of deaths occur when taking a wrong way, chosen due to inadequate evaluation of the traffic that particular day. It might be fruitful for health researchers to match the spatial-temporal representation of inhabitants of various communities showing the availability of hospitals to better identify gaps and disparities in its spatial-temporal accessibility (Guagliardo, 2004). Road traffic is characterized by a set of criteria namely travel time, road network structure state, and congestion. These criteria provide indices of vulnerability or criticality of the components (Manche, 2000). The vulnerability of the road network differs depending on the time during a day due to different traffic states conditions, such as free traffic and/or congestion (Eusofe et al., 2017; Gleyze, 2007).

Using all the characteristics of road traffic, several methods have been used to solve the problem of route selection: (Viljoen \& Joubert; Kim, et al., 2016; Leng et al., 2014; de Oliveira et al., 2014; Curl at el., 2011; Jun et al., 2008; Guagliardo, 2004). These methods make it possible to evaluate and define accessibility based on a decreasing distance depending on the original point of destination and the attractiveness of the destination using purely mathematical methods whose results are presented in the form of figures. In this article, the authors use spatial analysis tools provided by GIS such as Mapinfo, ArcGis, etc., to implement an algorithm that encompasses these criteria: structure, congestion, speed limit, travel time (Maltinti et al., 2012) and which relies on the distance of the algorithm in order to obtain an optimal route responding to accessibility problems. The WGS84 longitude/latitude with pin 30 west of Greenwich was used as the projection system for all the maps described in this article. The source for all the maps in this study was open street maps, and this produced the test bench (geographic database) for the algorithm.

The methodology is based on the implementation of the algorithm of the shortest path and the generalised temporal equation in order to obtain a better possible route while comparing the results with those obtained by the tools GIS 
(geographical information system) because this study seeks to define the accessibility indicator and the routes most used by drivers. The main aim of the study is to project on a case study (hospitals) in order to build in the future a cartographic simulation program allowing the probable distribution of ambulance drivers and to propose a global tool for measuring and monitoring quantitative and qualitative mobility between two hospitals in two districts: Chetouane and Tlemcen with the intention of mitigating damages caused by choosing an ineffective route. This approach can be applied to other road networks knowing their characteristics (structure, traffic, speed limit) following crucial surveys on the latter. This algorithm can provide an optimal solution in time for many other problems such as postal services (DHL, FedEx) or transport logistics companies (Flèche bleue). The main problem of this kind of company is not the distance, but rather the time because they must travel to the various destinations in shortest time. These criteria help to optimise their transport network to get the best quality of service and therefore have a positive impact on their earnings.

Thus, to quantify road network vulnerability, this research offers a method based on the material aspect which deduces the functional aspect through the structural aspect and also the generalised travel time demonstrated and evaluated previously for the choice of path.

\section{Study area: road network of Tlemcen city}

The development of any country is closely related to its communication networks. These contribute in the economic development through the exchange of products and serve as organs of communication between people with multiple implications (training, transport, health and cultural) that entail (Sunghoon et al., 2016; Chapelon, 1997). The road network of Tlemcen city includes, on the one hand, an inter-agglomeration network identified according to the administrative classification in national roads $(\mathrm{RN})$, wilaya roads (WR), and communal roads (CR) and on the other hand, a network of intra-agglomerations as presented in Figure 1. The whole territory of the city is connected to the main agglomerations by a network of national roads ( $\mathrm{RN} 22-\mathrm{RN} 7$ and $\mathrm{RN} 2$ ) ensuring the service of the urban area in the four directions North, South, East and West. The North direction is the most important in terms of the number of agglomerations served. Given the population of 949,135 inhabitants, the current strategy targets to formulate a transport model that would be the most appropriate in responding to the general trends in transport and travel needs scale of the territory, especially in case of emergency. The road network of Tlemcen city is shown in Table 1.

\section{Methodology}

Travel time performance is estimated based on travel time and its reliability. The concept of vulnerability will be defined from the sensitivity of the traffic to the 
disturbances. The vulnerability model will be based on generalised travel time (Lebacque et al., 2009; Wang et al., 2014). Therefore, the probability of degradation and the consequences (interruptions, traffic jams) are taken into account in this model, as well as the speed limit for each section.

Table 1 Characteristics of the road network

\begin{tabular}{cccc}
\hline Communes & Consistency $(\mathrm{km})$ & Road Width $(\mathrm{m})$ & NR \\
\hline Tlemcen & 26,828 & $7 \mathrm{~m}$ & RN22, RN7 and RN2 \\
\hline Mansourah & 16,690 & $7 \mathrm{~m}$ & RN22, RN7 \\
\hline Chetouane & 8,854 & $7 \mathrm{~m}$ & RN2 \\
\hline TOTAL & 52,372 & $7 \mathrm{~m}$ & $/$
\end{tabular}

Source: (Agence Nationale d'Autoroute, 2017)

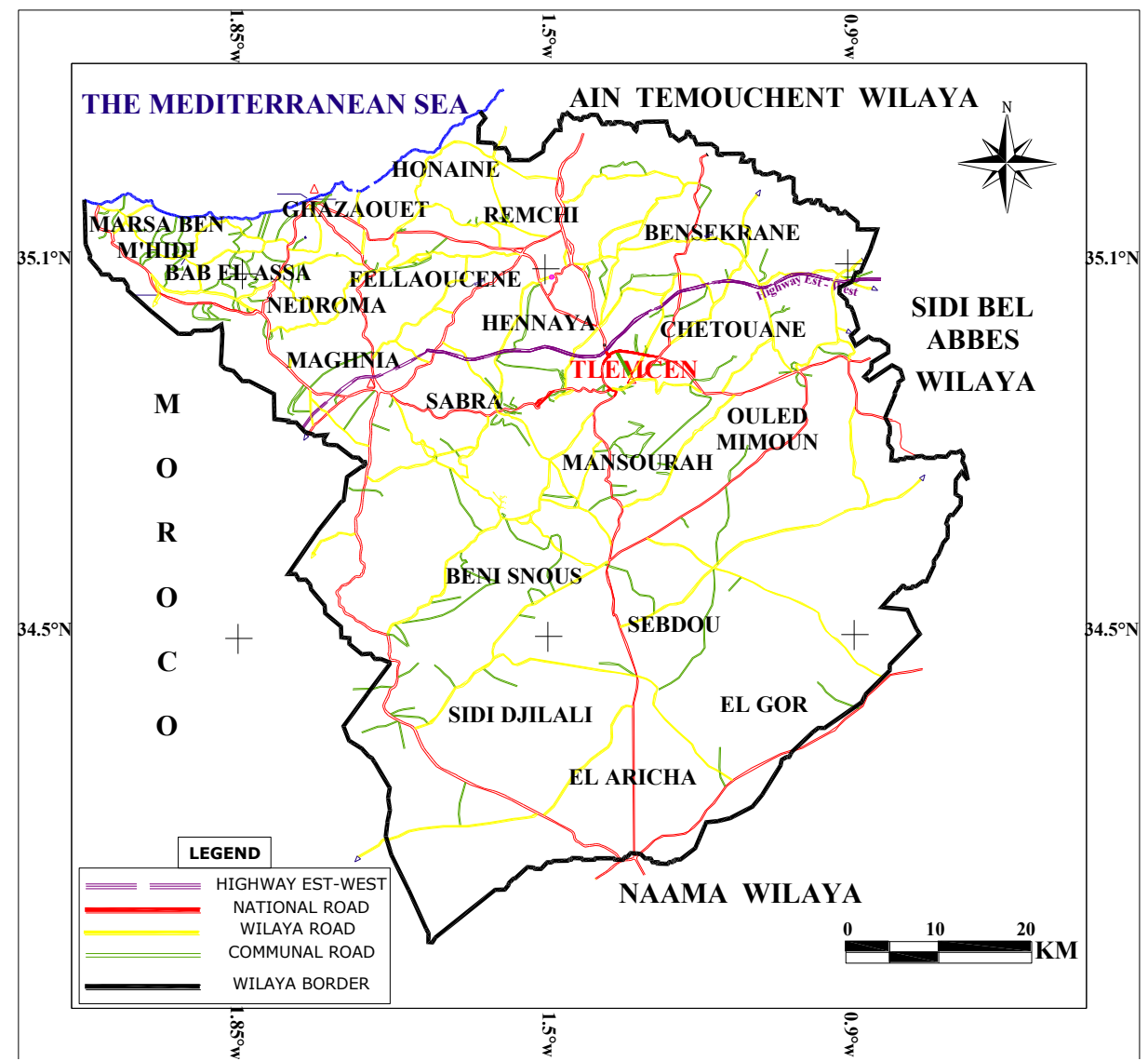

Figure 1. Road Network of Tlemcen city

The methodology consisted in developing methods for assessing the vulnerability and determination of vulnerable road segments in a road network using the concept of the travel time method (Maltinti et al., 2012) in order to find the shortest path equivalent to the shorter distance (Figure 2), taking into 
consideration all the indicators (travel time, distance, structure, speed limit, the state of the trunks (degrees of vulnerability) (Gleyze, 2005) that perceive the network only by means of optimality criteria and take into account the potentialities offered by the possible existence of alternative paths (equivalent to the optimal path), which were presented in this context in the form of maps deduced by a program implemented in a GIS platform (MapInfo). This study concerns the territory of Tlemcen northwest of Algeria. The travel time reliability is one of the most significant indices for an operational research study of a road network. Asakura \& Kashiwadani (1991) proposed that travel time fluctuation can be used to estimate the reliability of the transportation network given the state of its structure and its degradations as well as the speed limit. The reliability formula of the transit time journey was derived from works by An et al. (2014):

Where:

$$
\mathrm{R}_{\mathrm{a}}=\mathrm{P}\left[\mathrm{T}_{\mathrm{a}} \leq \mathrm{t}_{\mathrm{a}}(1+\delta)\right]
$$

$\mathrm{R}_{\mathrm{a}}$ : travel time reliability of the road segment a

$\mathrm{t}_{\mathrm{a}}$ : free travel time on the road segment a

$\delta$ : the increasing ratio of the acceptable travel time for travellers to free travel time

$\mathrm{T}_{\mathrm{a}}$ : generalised travel time on the road segment a

In general, people in different areas or different road segments can tolerate congestion to varying degrees. So, this time $\delta$ should be different for different road segments. In calculating the reliability of travel time, the function used to calculate the travel time of the road segment is as follows:

$$
\mathrm{T}_{\mathrm{a}}=\mathrm{t}_{\mathrm{a}}\left[1+\beta\left(\frac{x_{a}}{c_{a}}\right)^{\mathrm{n}}\right]
$$

Where:

B,n: parameters of the BPR function

$\mathrm{x}_{\mathrm{a}}$ : traffic volume on the road segment a

$\mathrm{C}_{\mathrm{a}}$ : capacity on the road segment a

$\beta, \mathrm{n}$ can be calibrated according to the observation data obtained in the field. The recommended values are $B=0.15, \mathrm{n}=4$. The substitution of equation 2 for equation 1 gives:

$$
\mathrm{R}_{\mathrm{a}}=\mathrm{P}\left[\mathrm{c}_{\mathrm{a}} \geq \mathrm{x}_{\mathrm{a}}\left(\frac{\delta}{\beta}\right)^{-1 / \mathrm{n}}\right]
$$

Where:

$\mathrm{R}_{\mathrm{a}}$ : travel time reliability of the road segment a

Since the $\mathrm{C}_{\mathrm{a}}$ capacity is a random variable, it must undergo a certain probability distribution. Suppose its distribution function is $\mathrm{FC}_{\mathrm{a}}(\mathrm{x})$, then

$$
\begin{aligned}
& \mathrm{R}_{\mathrm{a}}=1-\mathrm{FC}_{\mathrm{a}}\left(\frac{\delta}{\beta} \mathrm{\delta}_{\mathrm{a}}^{\frac{-1}{n}} \mathrm{x}_{\mathrm{a}}\right. \\
& \mathrm{r}_{\mathrm{a}}=1-\mathrm{R}_{\mathrm{a}}=\mathrm{FC}_{\mathrm{a}}\left(\frac{\delta}{\beta}^{\frac{-1}{n}} \mathrm{x}_{\mathrm{a}}\right)
\end{aligned}
$$

Where:

$r_{a}$ : the probability that the road segment a cannot meet the required reliability 
Moreover, $\mathrm{R}_{\mathrm{a}}$ can be considered as the disutility linked to the reliability of the journey time. Reliability of the journey time for the Rk route can be represented as:

$$
\mathrm{R}_{\mathrm{k}}=\prod_{\mathrm{a}} \mathrm{Ra} \delta_{\mathrm{ak}}
$$

Taking into account alternative paths would enrich the notion of accessibility. Reducing travel time and increasing reliability are the two desiderates of travellers, but these two objectives are generally contradictory and cannot be fulfilled at the same time (An et al., 2014). In the vulnerability analysis, the authors looked for the minimum value of the travel time when the traffic flow is disturbed. So the generalised travel time can be defined as the weighting of the ratio between the actual travel time, free travel time and the unreliability of travel time. The formula to calculate the generalised travelling time could be written as:

$$
\mathrm{T}_{\mathrm{ga}}=\mathrm{\eta}\left(\frac{T_{a}}{t_{a}}\right)+(1-\eta) \mathrm{r}_{\mathrm{a}}
$$

Where:

$\mathrm{T}_{\mathrm{ga}}$ : generalised travel time on road segment a.

$\eta$ and $1-\eta$ both reflect the attitude towards travel time and its reliability in the generalised travel time. With larger $\eta$ and smaller $1-\eta$, the variation of travel time should be focused on its analysis. Conversely, more attention needs to be paid to the variation in reliability. Also, $0<\eta<=1$, when $\eta=1$, this means that the general analysis of the travel time must be based on the total travel time, regardless of the reliability of the journey time. On the other hand, when $\eta=0$, the analysis will be entirely based on the reliability of the travel time, without taking into account the variation of the travel time. In the previous equation it can be seen that the generalised travel time is related to the volume of traffic circulation and has no relation with the volume of traffic on the other road segments. These characteristics can be reformulated in a mathematical form (An et al., 2014):

$$
\begin{aligned}
& \frac{\partial T_{\text {_ga }}\left(\mathrm{x}_{-} \mathrm{a}\right)}{\partial_{-}\left(\mathrm{x} \_\mathrm{a}\right)}>0 \\
& \frac{\partial \mathrm{T}_{-} \mathrm{ga}\left(\mathrm{x} \_\mathrm{a}\right)}{\partial_{-}\left(\mathrm{x} \_\mathrm{b}\right)}=0, \mathrm{a} \neq \mathrm{b}
\end{aligned}
$$

From what we can see from traffic data, it is obvious that less travel time value crates an optimum road in the network and vice-versa. Hence, the utility function is defined as the opposite of the generalised travel time, presented as:

Where:

$$
\mathrm{e}_{\mathrm{a}}=\frac{1}{T_{g a}}
$$

$\mathrm{e}_{\mathrm{a}}$ : utility of the road segment a.

The authors also considered a utility index to characterise the operational performance of land transport using the relationship between the change in value of the utility index and the primary utility index to reflect the fragility with which traffic could be disrupted by events. The vulnerability formula can be written as:

$$
\mathrm{V}_{\mathrm{j}}=\frac{e_{j}^{0}-e_{j}}{e_{j}^{0}}
$$

Where:

$e_{j}^{0}$ : initial utility index of the road segment $\mathrm{j}$ 
$e_{j}$ : disturbed utility index of the road segment $j$

The entire vulnerability of the road network can be calculated using the formula put forward by An et al. (2014):

$$
\mathrm{V}_{\mathrm{R}}=\sum_{\mathrm{i}=1} \mathrm{j}_{\mathrm{i}} \mathrm{V}_{\mathrm{i}}
$$

Where:

$\mathrm{w}_{\mathrm{j}}$ : weight of the road network unit $\mathrm{j}$

$\mathrm{v}_{\mathrm{j}}$ : vulnerability of the road segment $\mathrm{j}$

In this research, the authors measured the appropriate path within Tlemcen road network by using graphical cards. The arc travel time is defined as by An et al. (2014):

$$
\mathrm{T}_{\mathrm{a}}=\mathrm{t}_{\mathrm{a}}\left[1+0.15\left(\frac{X_{a}}{C_{a}}\right)^{4}\right]
$$

\section{Implementation of study data in a GIS}

Simulations were performed using the principal road network of Tlemcen city, with an area of $1404 \mathrm{Ha}$, divided into four categories with the following speed limits:

$\begin{array}{lll}\text { - } & \text { Highway } & -120 \mathrm{Km} / \mathrm{h} \\ \text { - } & \text { National Road } & -80 \mathrm{Km} / \mathrm{h} \\ \text { - } & \text { Wilaya Road } & -50 \mathrm{Km} / \mathrm{h} \\ \text { - } & \text { Communal Road } & -40 \mathrm{Km} / \mathrm{h} \\ \text { - } & \text { Track (Secondary Road) } & -20 \mathrm{Km} / \mathrm{h}\end{array}$

The authors loaded the road network of Tlemcen, using the software MapInfo and Mapbasic. The network categories are differentiated by four colors: red for the national roads, yellow for city roads, green for communal road, and magenta for the secondary roads (Figure 2).

This application on the network of the Tlemcen city according to movement demand between the hospital of Tlemcen and the hospital of Chetouane unfolds on the following points:

\section{Georeferencing}

The study requires a spatial representation of the road. Thus, it's necessary to fix the particular objects, which are defined by the geo-referencing of vertices. The georeferenced data is populated by a series of coordinates that identify a position expressed in a well-defined coordinate system. The georeferencing of vertices is reflected on that of the edges (or arcs) because these components are entirely determined by the vertices present at their ends (Bedel, 2010).

\section{Valuation}

The topological presentation provided by the graphs theory shows that the edges (or arcs) are equivalent in terms of valuations. In fact, the modelling of the transportation network, graph theory, considers an evaluation operation. The evaluation of the edges (or arcs) of a graph consists in attributing to them costs, 
representative - in the case of transport networks - of the modalities of displacement that one wishes to model within our network: distances, time, monetary cost, congestion, degradation, etc. (Erath et al., 2009).

\section{Labelling}

The study of road networks in a geographical context requires sizing vertices and discriminating them according to their size or relative importance. For this purpose, the graph theory considers the "labeling" operation. Vertices labelling of a graph located on the map consists of weighting. This means to assign them weights representative of their size or the importance they play in the road network of Tlemcen city: area, population, activity, offer, demand, etc. (Revaux \& Sander, 2000).

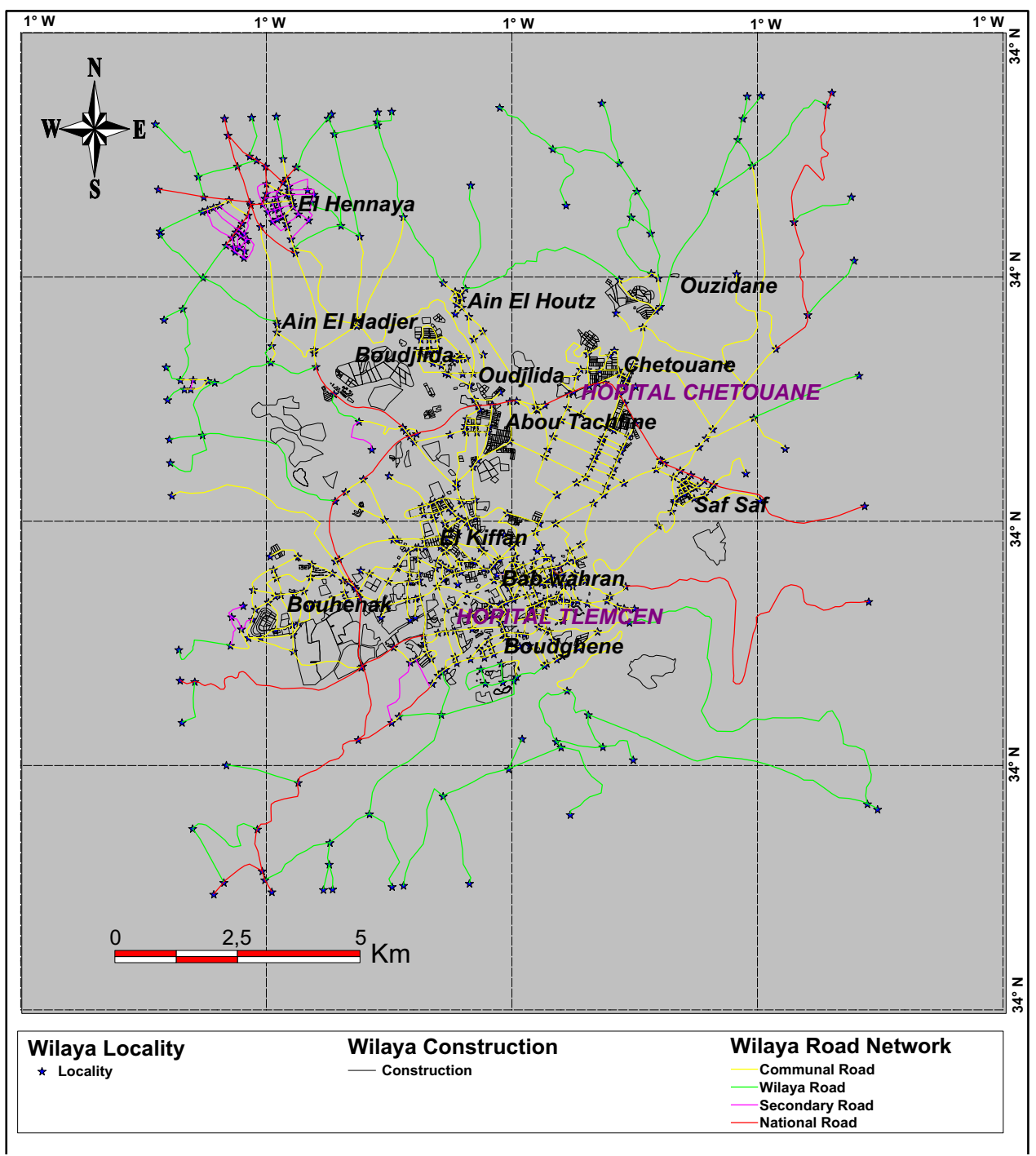

Figure 2. Map of the road network of Tlemcen Wilaya 


\section{Results in the GIS platform}

The efficiency of the road system is evaluated by its fluidity, time control, transport condition and movement. (Sullivan et al., 2010). The transportation system should meet urgent requests which cause a significant handicap for travellers, especially in some towns that were actually designed as exchange poles in some municipalities which are now folded on poles of exchange.

Figure 3 represents the study area's network roadmap according to the degree of vulnerability (Guo \& Xiong, 2014) that is summarised according to parameters such as the structural state of each road section, and the speed limit for each section and the traffic jam recorded during the day. These parameters are deduced from field surveys and implemented under a GIS platform. The authors focused on information efficiency related to changes in behaviour induced by population and their orientation towards roads structurally weak or congested, given the users' number and the speed limit for each road section in the network (Viljoen \& Joubert, 2018; Jenelius \& Mattsson, 2012).

The path chosen by the program and presented on the map by blue in Figure 4 represents the shortest path between the two hospitals (Tlemcen \& Chetouane). However, this path takes into consideration the distance and ignores other factors such as speed limit, structural weakness and congestion that may exist during a day. The vulnerability issue of the study area's road system aims, in particular, to better understand links between transport scheduling and their operating knowing that the study area includes two different municipalities, one is Chetouane, and the other is Tlemcen. The case study focuses on particular points, in order to select the better road between the two hospitals:

- System theory, which provides the methodological keys facilitating the identification of the critical elements in a road network given their configurations;

- $\quad$ Graph theory to design the transport network (level = transport supply);

- Multi-agent systems, to represent users as agents with various characteristics and rules of behaviour (Chapelon, 1998).

The simulation carried out using GIS platform, including the constraints of the network structure and the speed limit on these sections gives the path selected by the latter which is represented in blue in Figure 5 . The chosen route passes through the agglomeration of Abou Tachfine, which is the junction point between the new urban areas in the north and the centre of Tlemcen and the exit of the semi-industrial zone, all the flows passing through the centre of Tlemcen which usually experiences heavy traffic, causing a deterioration of the pavement which in turn induces a low level of service in terms of transport. Occasional imbalances of the road network on the service of Bab-Oran toward Tlemcen and towards the hospital translate most often in congestion problems and traffic jam. In this case, the shortest distance was calculated as a function of the structural state of the sections and the speed limit to travel between the two hospitals. 


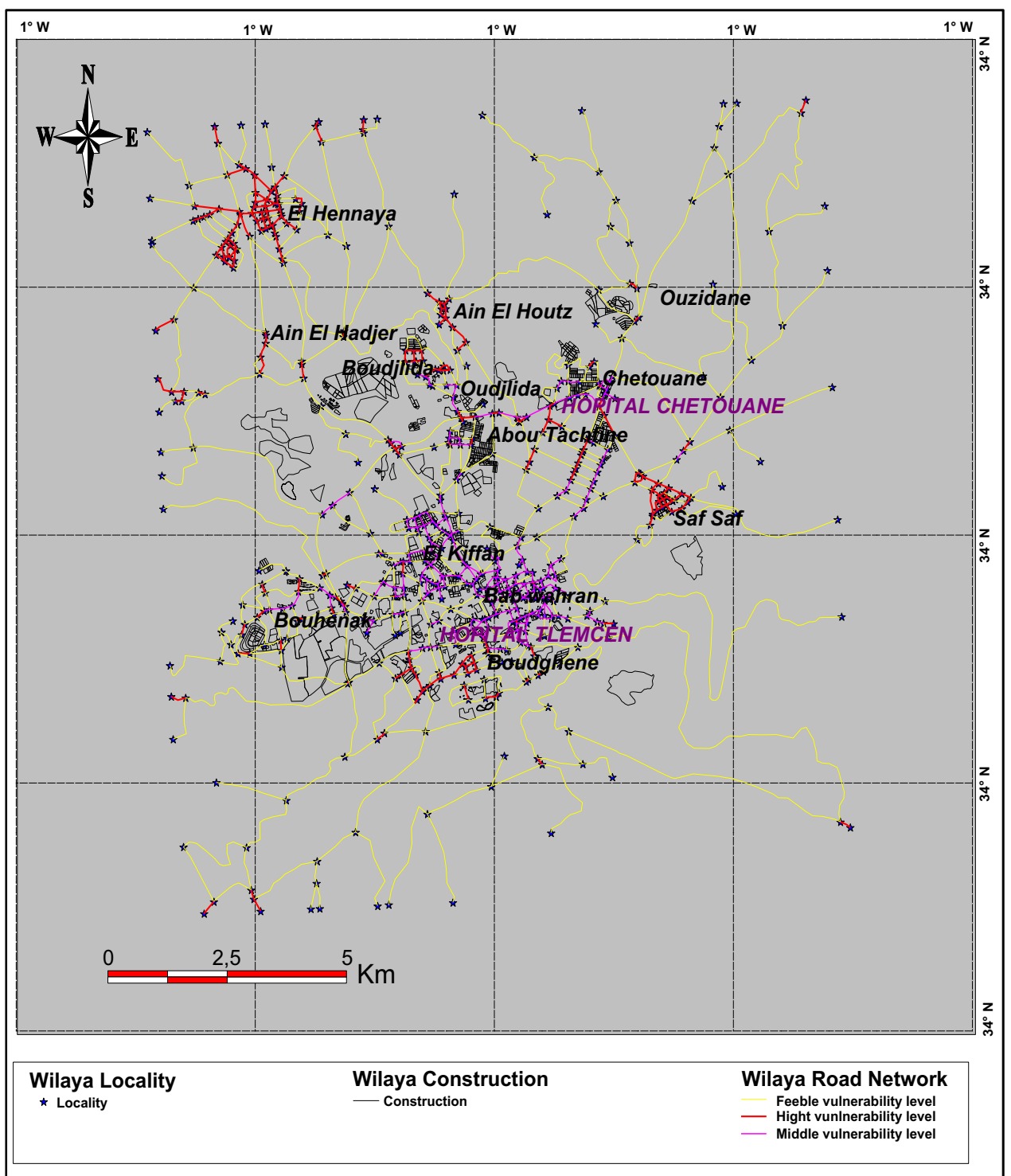

Figure 3. The structural state of the road network of Tlemcen city

Accesses to reach Tlemcen hospital through El Kiffan centre covers sections with a huge load, multi-functional and experiencing significant congestion given the speed limit of $20 \mathrm{~km} / \mathrm{h}$. This situation is not stable because it marks significant congestion especially during the peak hours of a day. Access to these areas leads to conflict points and permanent congestion which make intersections managements not efficient. This is particularly the case for the Bab Oran and EL Kiffan crossroads intersected by the road which ensures the connection and convergence of different flows to the city centre (Agence Nationale d'Autoroute, 2017). 


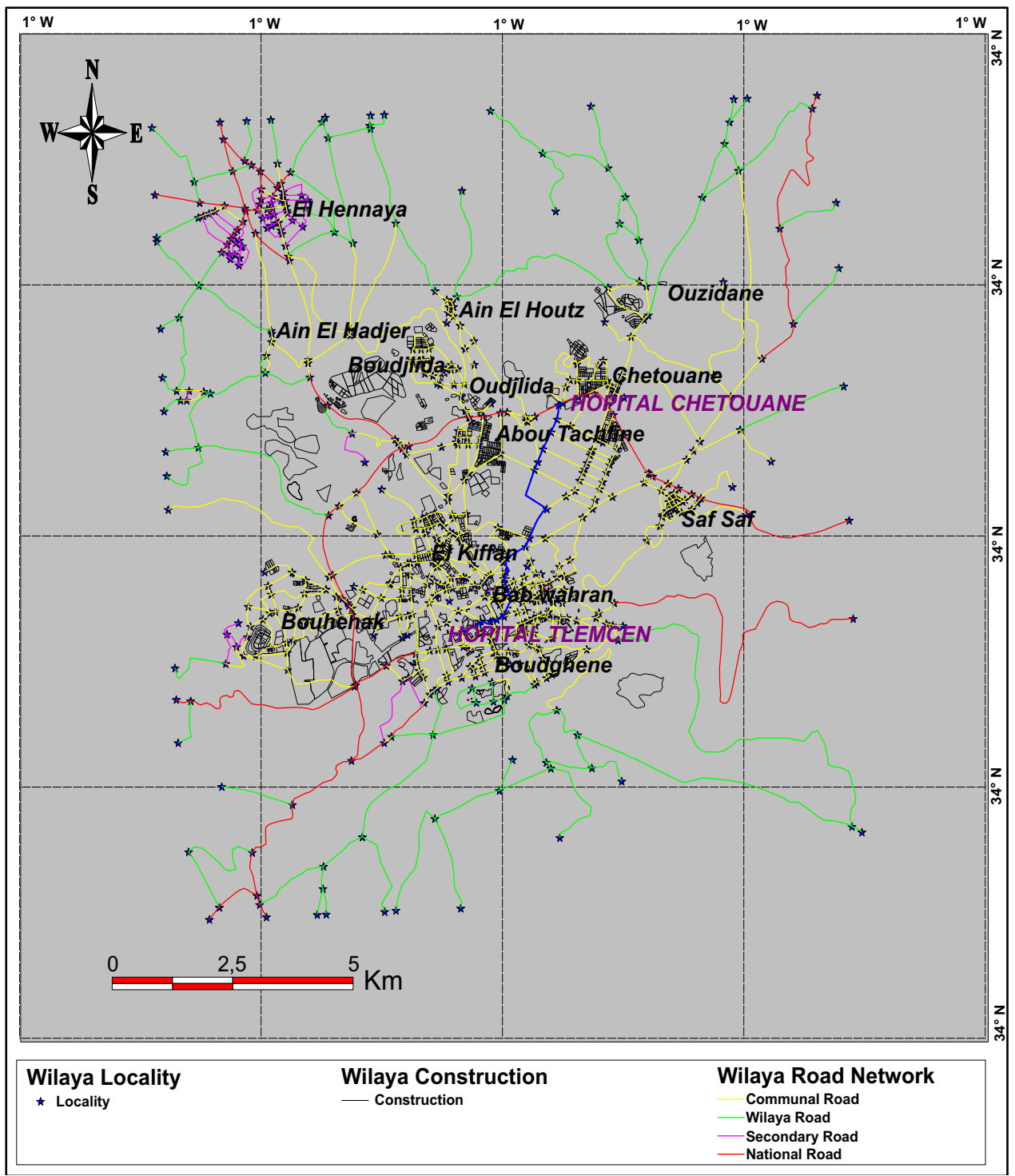

Figure 4. The shorter path between the two hospitals

The path drawn by the GIS platform, which takes into account all the factors and is presented in Figure 6 defines the road bypass of Tlemcen city drawn in blue. It makes it possible to divert heavy truck traffic to the south (Sebdou) and the east (Sidi Bel Abbès). It also depicts good geometric characteristics. The location choices of these hospitals focus on a peripheral belt that stretches discontinuously from east to west along the ring road. In the majority of cases the realisation of equipment and construction are not synchronic. Thus, far from being homogeneous, this peri-urban habitat belt contains vulnerable neighbourhoods that require integration. Therefore, this peri-urbanisation could only lead to a first socio-spatial differentiation. 


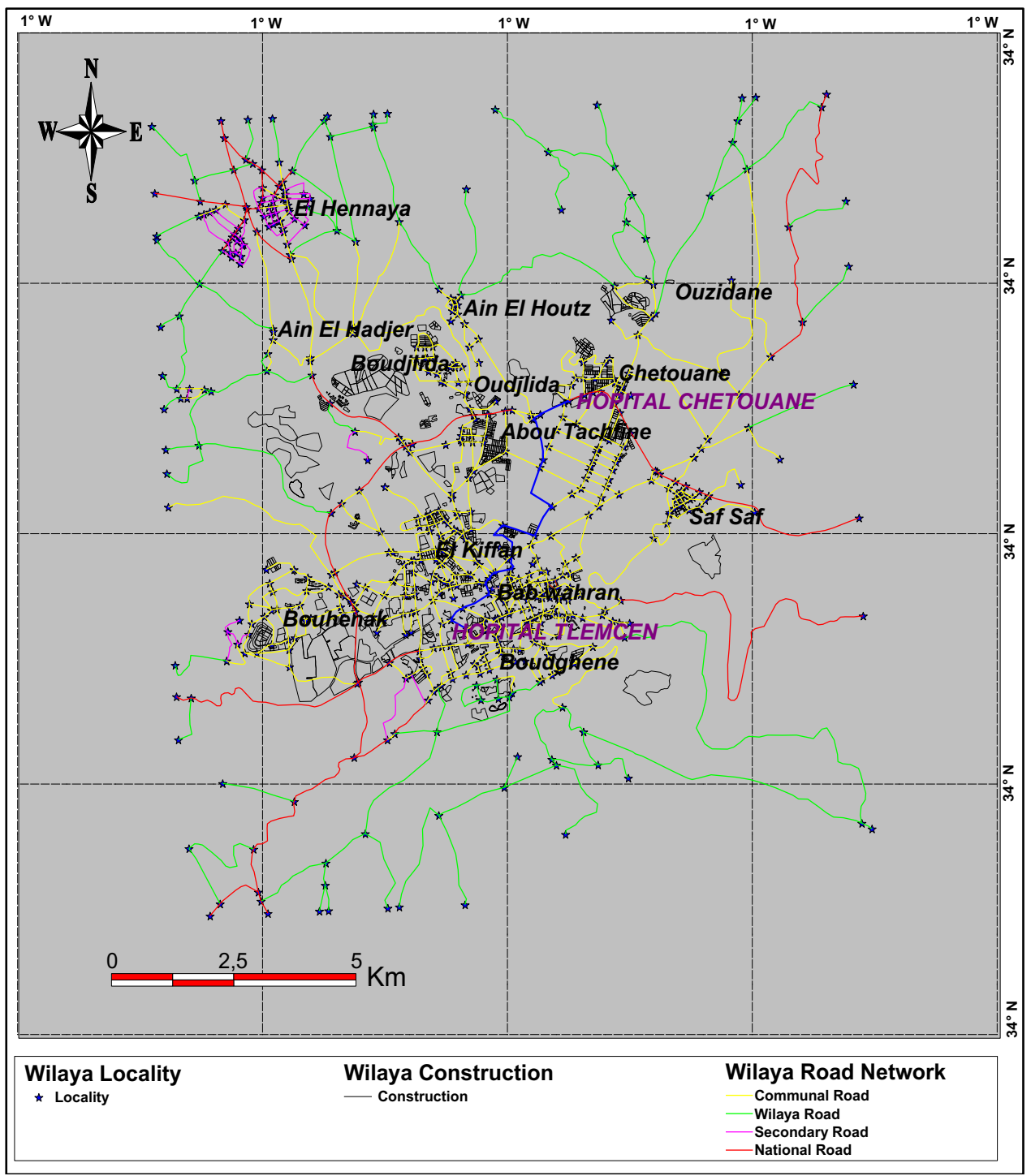

Figure 5. Shortest path between (O-D) in structure and speed

The healthcare infrastructure of the study area highlights:

- A dense network of structures for all types of health care

- A multiplication of small units spread all over the territory to ensure access to first aid for all urban areas including peripheral areas

- $\quad$ Strong integration of the private sector at all levels of health care.

Figure 6 proves that Tlemcen is a major pole, given the importance of the roads that it contains. The ring road is the axis that articulates the maximum of agglomerations: Mansourah, Chetouane and all secondary agglomerations. Its role is highly significant for the service of the whole urban population and also its width and its coherent structure following a good state of the land infrastructure and also the speed limit and the very short travel time. 


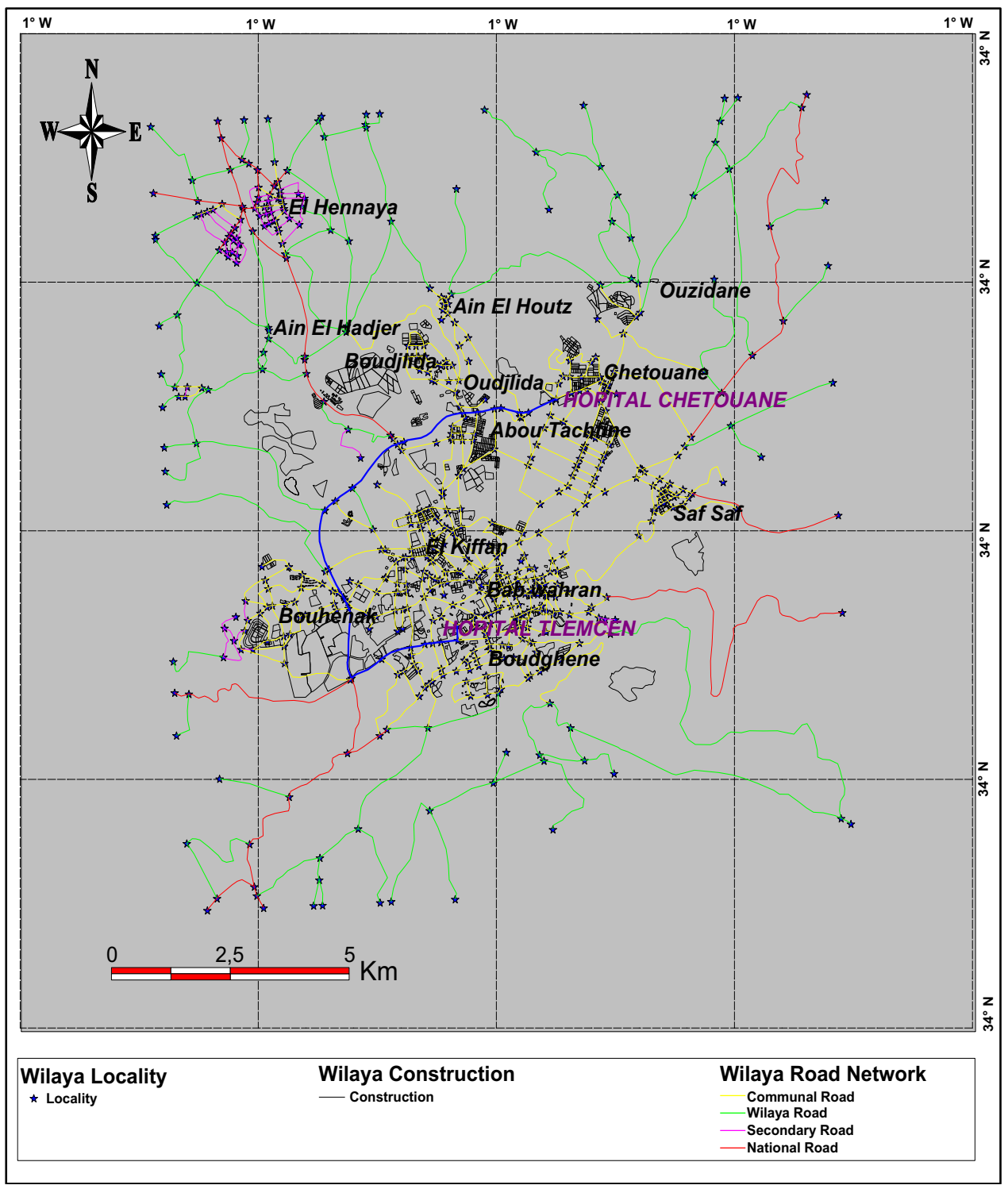

Figure 6. Shortest path between (O-D) in the favourable case

\section{Discussion and interpretation}

The strategic nature of the transport function in Tlemcen city derives from the scope it covers, considering the assumption of responsibility people and goods mobility within a territory. The three parameters introduced in the realised GIS platform include the shortest distance, speed limit, and travel time of each section. Other parameters included were the speed limit and the choice of origin towards the destination. The system of road network projected on the map and the right path selection in terms of distance between the two hospitals according to travel time implied people mobility issues and necessarily tends towards quantitative 
performance and qualitative means and implemented transport modes. The large population of Tlemcen requires mapping shortest paths between two pairs of nodes located a priori on the northeast and southwest axes. By comparing results previously gained, the question asked to a user is to observe if the produced last cards help him to understand the important role played by the most asked path in a shorter time.

The two figures 4 and 5 allows the user to map the path which frequently takes a part of the way through Bab-Oran while going towards Tlemcen hospital. This leads to reducing the relational space on the map to relations issues from the interest node. A shorter path indicator is mapped to understand the organisation of the structure when the relational set is reduced, regardless of the congestion and state of the network without committing to the speed limit allowed on each road section. Results gained by the model integrated into GIS and illustrated by Figure 6 are compared to those obtained by Route Finder (commercial software), by keeping the same database of Tlemcen network. Based on the accessibility map provided according to the data transmitted to the RouteFinder software, the periphery remains crucial for the study area as shown by Figure 7 .

Figure 7 illustrates that accessibility in the Tlemcen city is divided into two levels following the two colors according to the time of day and according to the state of the road. This data is more important when operating emergency cases. The model includes possible congestion effects, and the generalized cost is based on a linear combination of travel time and distance. However, results should be treated with care because the network database includes town streets, because the proposed optimal route based on the travel time provided by the RouteFinder software in Figure 8 match our result.

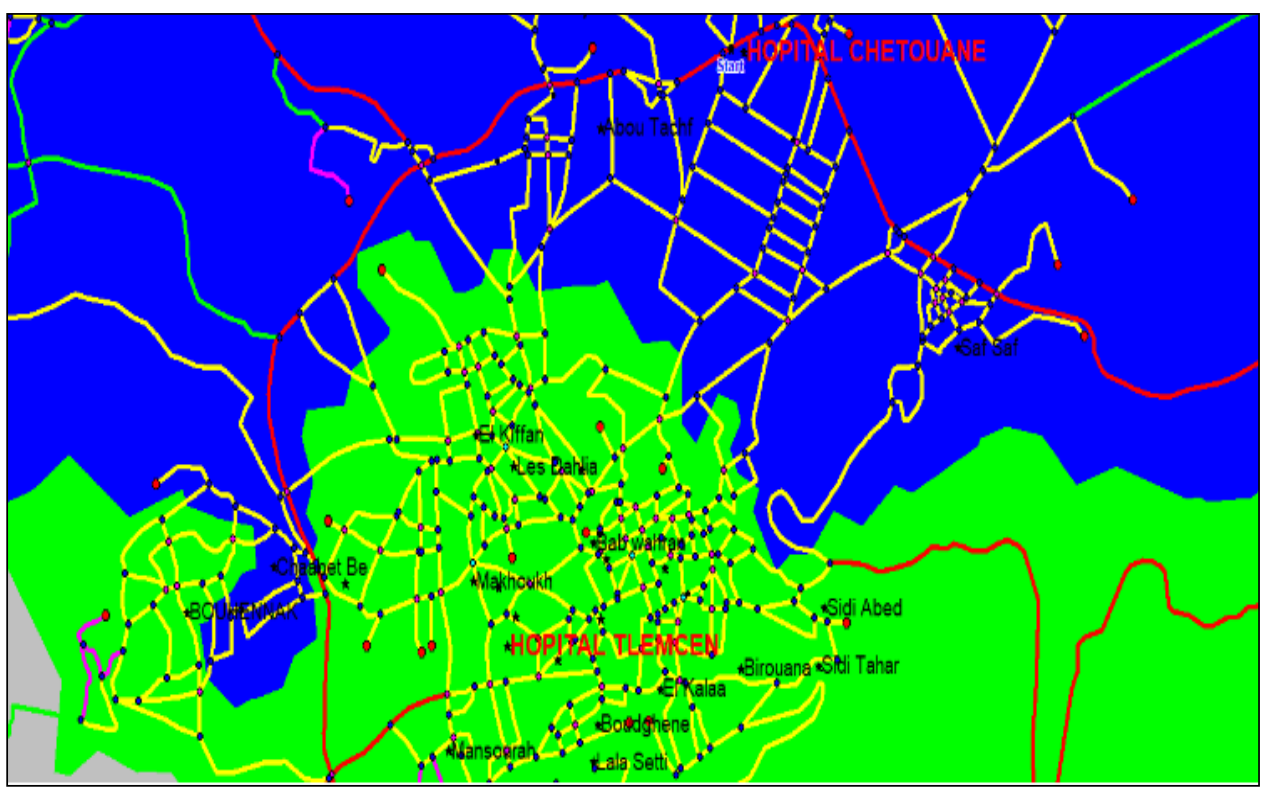

Figure 7. Accessibility Map Between the Two Hospitals (Route Finder) 


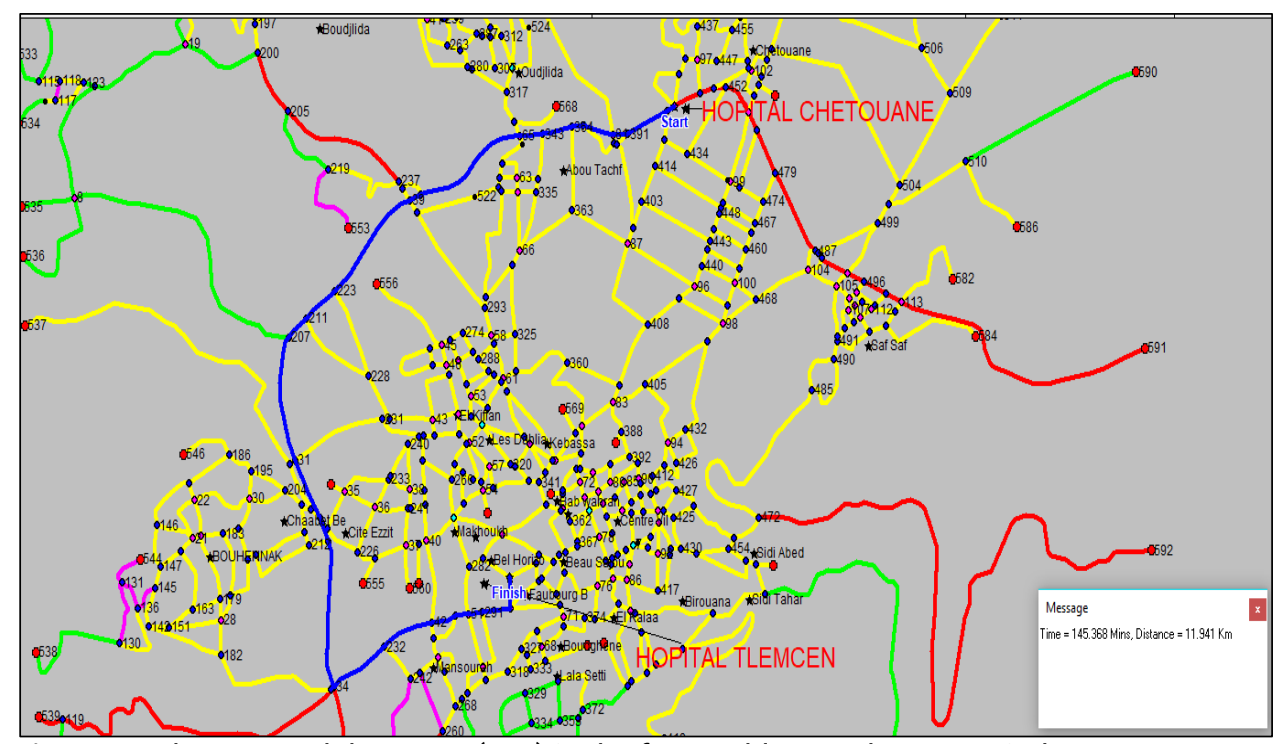

Figure 8. Shortest path between (O-D) in the favourable case by RouteFinder

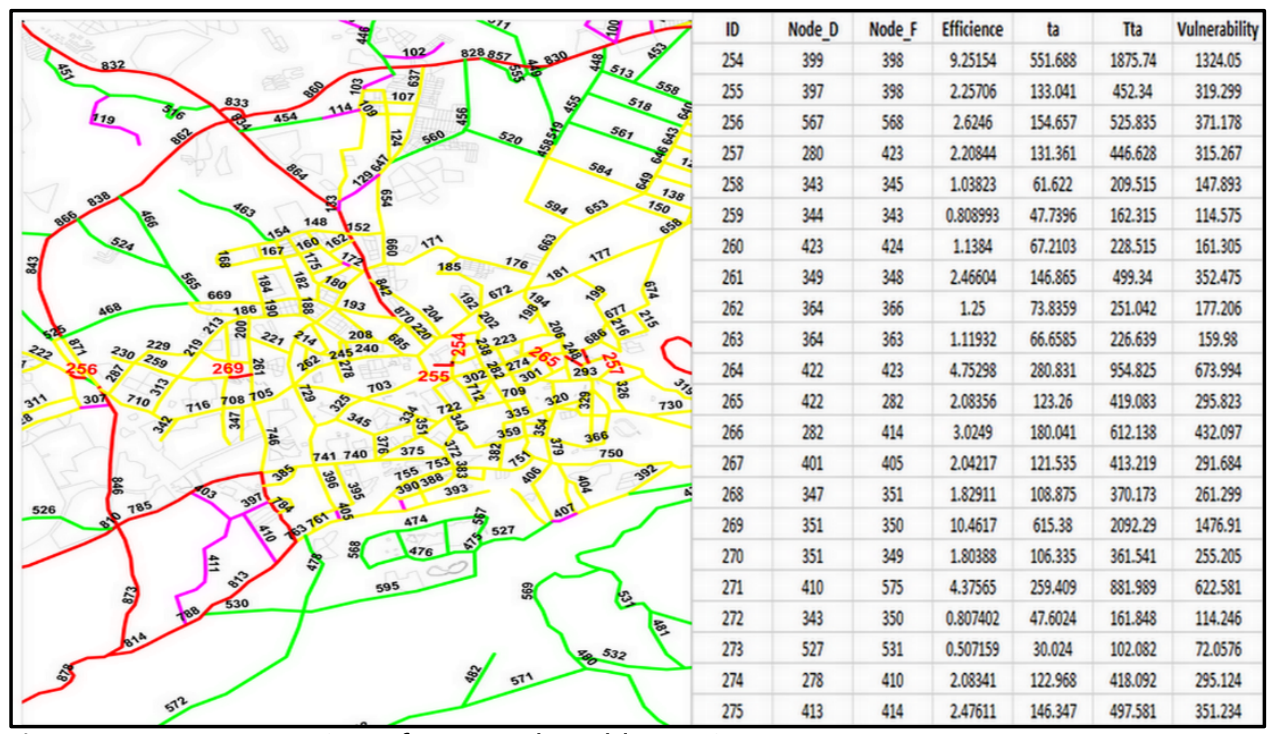

Figure 9. A summary view of some vulnerable sections

Figure 9 shows some vulnerable sections drawn in red depicting substantial congestion translated by time waste and is generally focused in the centre of Tlemcen road network.

The research's goal is to illustrate to the user which indicator (distance, travel time, congestion, speed limit) highlights the most demanded component of the road network according to its structural state. Figures 6 and 8 show the crossing of the three indicators between the two hospital destinations of Tlemcen and Chetouane which allows choosing a viable path and represents an accessible and 
fastest route. This illustration by graphic language allows comparing these results to other studies, considering vulnerable sections mapped in Figure 3. The concept of generalised travel time has been introduced to evaluate the efficiency of this road network system. The external disturbance impact (congestion, traffic, road conditions) on travel time and its reliability are both taken into account.

Therefore, generalised travel time includes both quantity and probability. Thus, to quantify road network vulnerability, this research offers a method based on the material aspect which deduces the functional aspect through the structural aspect and also the generalised travel time demonstrated and evaluated previously. This depends on the speed limit for each section studied, especially for the most two far healthcare services (Tlemcen and Chetouane hospitals). Nevertheless, results gained by the proposed algorithm lead to a more accurate approach compared to those of RouteFinder. This new approach can be another indication of the great importance of this road. Also, RouteFinder offers a map of Figure 10 for the distribution of traffic volume in all the states mentioned above with adequate meaning.

Figure 11 illustrates results gained by the algorithm implemented in GIS MapInfo Platform.This comparative summary allows the exploration of the road network following its marked vulnerability on its various road sections. Despite the fact that the optimal path is so longer that others, it represents a functional aspect, which ensures a good service and a good relationship between the communes of Tlemcen city, it seems a shorter path in time (generalized travel time). Table 2 illustrates the results provided by the algorithm developed by the authors.

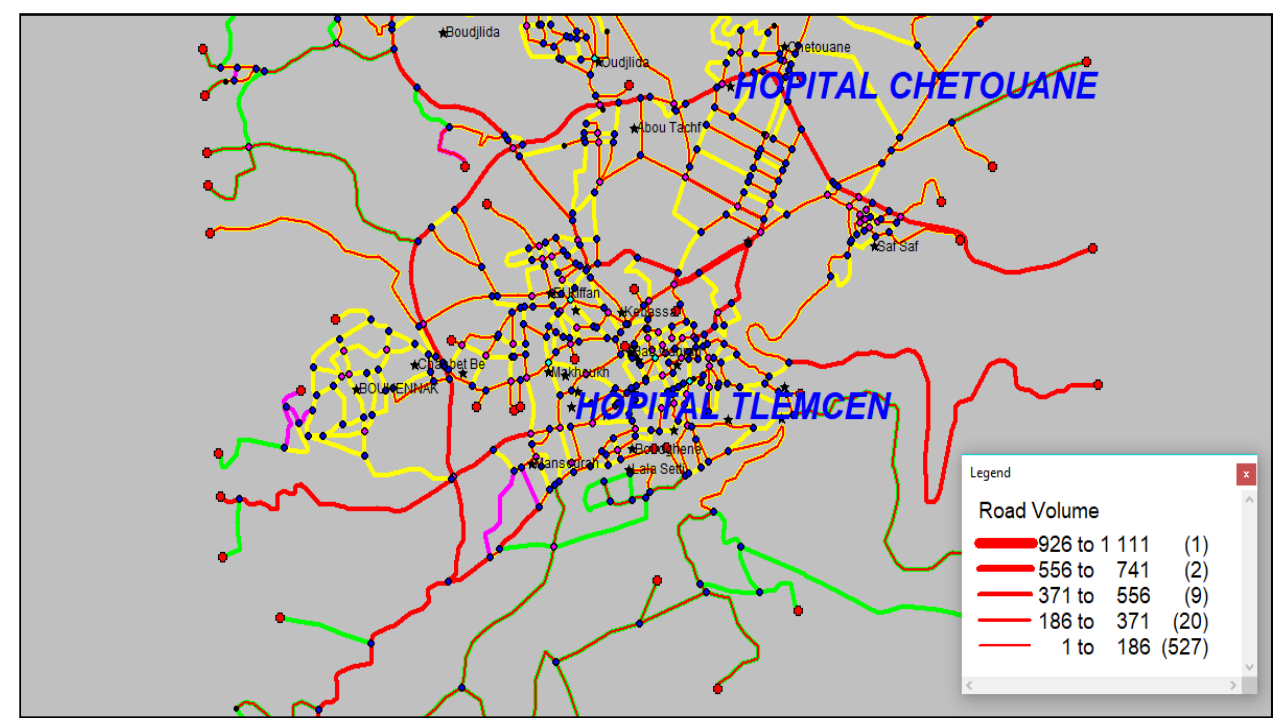

Figure 10. Traffic distribution of the wilaya road network 


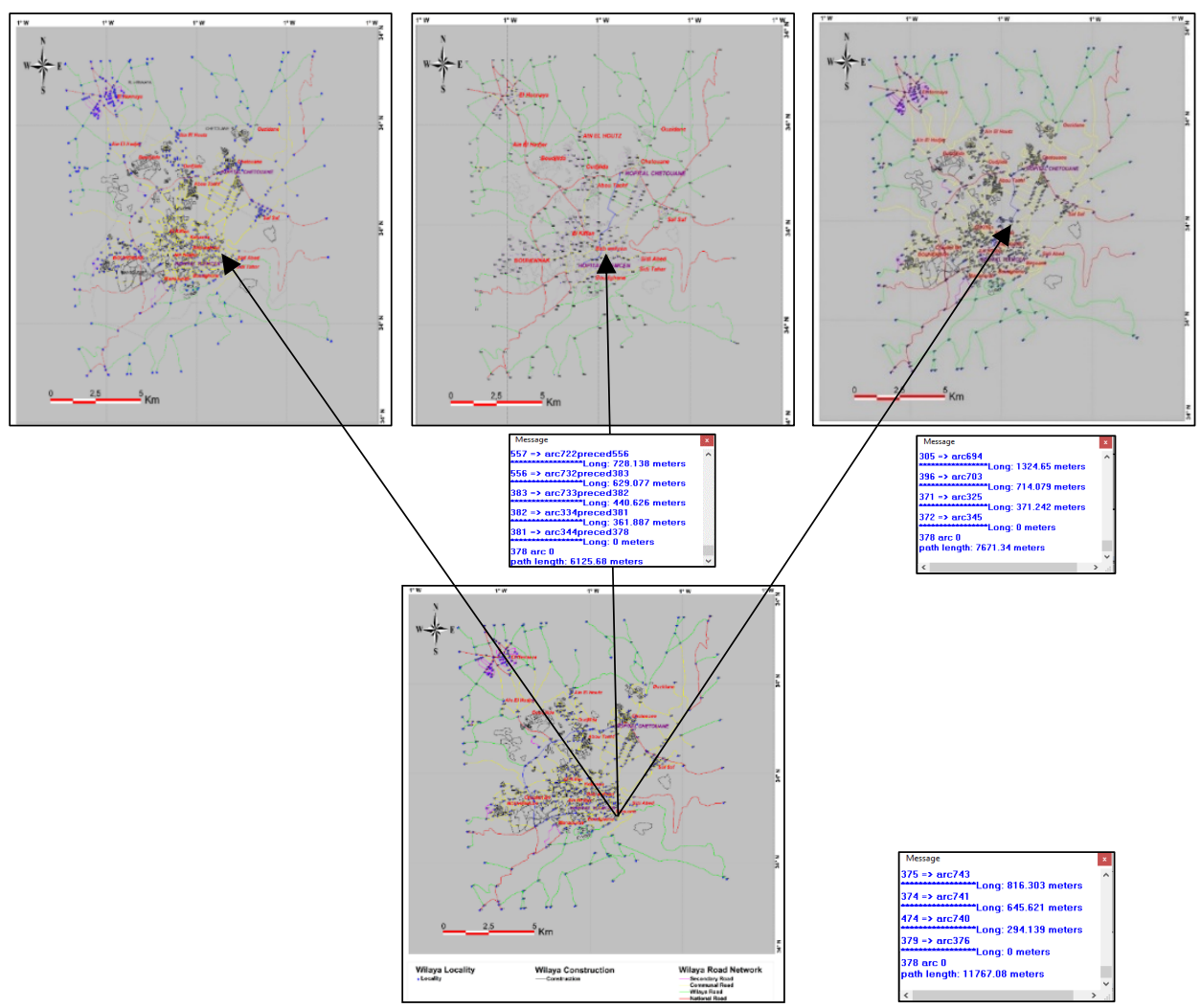

Figure 11. Synthesis of assembly of the road network maps

Table 2. Comparing the results of the obtained maps

\begin{tabular}{|c|c|c|c|}
\hline \multirow{2}{*}{ MAPS } & \multirow{2}{*}{ CRITERIA } & \multicolumn{2}{|c|}{ RESULTS } \\
\hline & & Level vulnerability & Distance /Time \\
\hline Figure 4 & Based on criterion: distance. & $\begin{array}{l}\text { Shorter path with high } \\
\text { degree of vulnerability }\end{array}$ & $\begin{array}{l}6,125.68 \mathrm{~m} / \\
28.377 \mathrm{Mins}\end{array}$ \\
\hline Figure 5 & $\begin{array}{l}\text { Based on two criteria: distance, } \\
\text { state of road network (degree } \\
\text { of vulnerability). }\end{array}$ & $\begin{array}{l}\text { Shorter path with } \\
\text { medium degree of } \\
\text { vulnerability }\end{array}$ & $\begin{array}{l}7,671.34 \mathrm{~m} / \\
\text { 23.223 Mins }\end{array}$ \\
\hline Figure 6 & $\begin{array}{l}\text { Based on three criteria: } \\
\text { distance, state of road network } \\
\text { (degree of vulnerability), travel } \\
\text { time. }\end{array}$ & $\begin{array}{l}\text { Shorter path with low } \\
\text { degree of vulnerability }\end{array}$ & $\begin{array}{l}11,767.08 \mathrm{~m} \\
/ 18.825 \mathrm{Mins}\end{array}$ \\
\hline
\end{tabular}

\section{Conclusion}

This research focuses on implementing a new way to achieve the shortest path within an urban transport network. Its method is comparable to different algorithms implemented in a GIS environment by implementing three factors: 
state of the network structure, journey time, congestion and the shortest distance presented in maps.

The analysis is based on studying different paths that provide linking between two healthcare facilities (hospitals). This allows evaluating the efficiency of a road network based on various traffic conditions, while the shortest path study does not take in consideration if a road network is traffic-free in order to avoid congestion for critical services. While knowing that the choice of a route which ensures a good service is mandatory for traffic management during the day, one can evaluate the road network performance when selecting the right path for critical services, taking into account the structural vulnerability which leads to a functional vulnerability. The implementation of sections speed limits and travel time within GIS platform ensures better monitoring of the network' performances, especially for critical services as healthcare facilities. However, other considerations should be outperformed. The proposed method is done on Tlemcen road network and is not suitable for large networks.

The proposed index should be further developed to broaden the application scope. Moreover, correlation studies between vulnerability, distance and travel time criteria should be deeply evolved for choosing the efficient route between two specific destinations. With this methodology, ambulance drivers are assisted to make a better decision when choosing the best path to reach their destination (hospital) in the shortest time possible. Therefore, reducing the number of deaths on board.

Finally, this study is a gateway to other researches that aim to meet and deal with the various challenges on the road transport infrastructure by controlling the travel time during specific periods. Vulnerability analysis of road networks acts as a framework using different aspects of transport reliability studies as its foremost tools. In the proposed method, the authors tried to implement all criteria which can disturb or block traffic flow in a realistic behaviour such as Tlemcen road network, and they compared the obtained results with other classical methods used by commercial software to approve the algorithm vis- a- vis the algorithm of shorter distance.

\section{References}

Agence Nationale d'Autoroute (A.N.A.T.) (2017), Un espace urbain de cohérence et de solidarité intercommunale. Étude de révision du schéma directeur de développement et d'urbanisme, Agence Nationale d'Autoroute, Algérie.

An S., Wang, J., Leng, J.Q. and Li, W. (2014), "Vulnerability of road network based on generalised travel time", Proceedings of the Institution of Civil EngineersTransport, vol. 168, no. 5, p. 425-433, Thomas Telford Ltd.

Asakura, Y. and Kashiwadani, M. (1991), "Road network reliability caused by daily fluctuation of traffic flow", in $19^{\text {th }}$ PTRC Summer Annual Meeting, University of Sussex, United Kingdom. 
Bedel, O., Ferré, S. and Ridoux, O. (2010), "GEOLIS: A Logical Information System for the Organization and Search of Geo-Located Data", Innovative Software Development in GIS, p. 151-187.

Chapelon, L. (1997), "Offre de transport et aménagement du territoire: évaluation spatio-temporelle des projets de modification de l'offre par modélisation multi-échelles des systèmes de transport", $\mathrm{PhD}$ Thesis, François Rabelais University of Tours, 24 May 2018, https://cutt.ly/ueDoSJC.

Chapelon, L. (1998), "L'accessibilité aux grandes infrastructures de transport: analyse et modélisation", in Nouvelles approches en géographie théorique et quantitative/Actes des troisièmes Rencontres Théo Quant tenues à Besançon les, no. 20, p. 157-166, Besançon, in French.

Curl, A., Nelson, J.D. and Anable, J. (2011), "Does accessibility planning address what matters? A review of current practice and practitioner perspectives", Research in Transportation Business E Management, vol. 2, p. 3-11.

de Oliveira, E.L., da Silva Portugal, L. and Junior, W.P. (2014), "Determining critical links in a road network: vulnerability and congestion indicators", Procedia-Social and Behavioral Sciences, vol. 162, p. 158-167.

Erath, A., Birdsall, J., Axhausen K.W. and Hajdin, R. (2009), "Vulnerability assessment methodology for Swiss road network", Transportation Research Record: Journal of the Transportation Research Board, vol. 2137, p. 118-126.

Eusofe, Z. and Evdorides, H. (2017), Assessment of road safety management at institutional level in Malaysia: A case study, IATSS Research, vol. 41, no 4, p. 172181 .

Gleyze, J.F. (2005), "La vulnérabilité structurelle des réseaux de transport dans un contexte de risques", PhD thesis, Paris 7 University, COGIT, 20 May 2018, https://cutt.ly/6eDoBxJ.

Gleyze, J.F. (2007), "Évaluation de la variété des chemins entre deux sommets d'un graphe-Le "nombre d'options équivalentes au plus court chemin”", The open archive HAL, 24 May 2018, https://cutt.ly/ueSyFFe.

Guagliardo, M.F. (2004), "Spatial accessibility of primary care: concepts, methods and challenges", International Journal of Health Geographics, vol. 3, no. 1.

Guo, X.Y. and Xiong, W.T. (2014), "Classification of the Road Network Vulnerability Based on Fuzzy Clustering Method", Advanced Materials Research, Trans Tech Publications, p. 1974-1983.

Jenelius, E. and Mattsson, L.G. (2012), "Road network vulnerability analysis of area- covering Disruptions: A grid-based approach with case study", Transportation Research Part A, p. 746-760.

Jun, S., Jian-Yuan, L., Han, C. and Xi-Li, W. (2008), "Study on near-optimal path finding strategies in a road network", Journal of Algorithms E Computational Technology, vol. 2, no. 3, p. 319-333.

Kim, S. and Yeo, H. (2016), "A flow-based vulnerability measure for the resilience of urban road network", Procedia-Social and Behavioral Sciences, vol. 218, p. 1323. 
Lebacque, J.P., Aron, M. and Aquiléra, V (coord.) (2007), Modélisation du trafficActes du groupe de travail 2007, IFSTTAR, 128 p.

Maltinti, F., Melis, D. and Annunziata, F. (2011), "Methodology for vulnerability assessment of a road network", paper presented at International Conference on Sustainable Design and Construction (ICSDC), 24 May 2018, https://cutt.ly/TeIid2C, p. 686-693.

Manche, Y. (2000), "Analyse spatiale et mise en place de système d'information pour l'évaluation de la vulnérabilité des territoires de montagnes face aux risques naturels", PhD Thesis, Joseph Fourier University - Grenoble I.U.F.R. of Geography, 4 April 2018, https://cutt.ly/reDo8Uy.

Revaux, P. (2000), Methodological gateways between freight and passenger transport. Final report, Special School of Architecture and University of Cergy Pontoise, Department of Geography, Laboratory of Mobilities Networks Territories Environments.

Sullivan, J.L., Novak, D.C., Aultman-Hall, L. and Scott, D.M. (2010), "Identifying critical road segments and measuring system-wide robustness in transportation networks with isolating links: A link-based capacity-reduction approach", Transportation Research Part A: Policy and Practice, p. 323-336.

Sunghoon, K. and Hwasoo, Y. (2016), "A Flow-based Vulnerability Measure for the Resilience of Urban Road Network", $11^{\text {th }}$ International Conference of the International Institute for Infrastructure Resilience and Reconstruction, Republic of Korea.

Viljoen, N.M. and Joubert, J.W. (2017), "The Road Most Travelled: The Impact of Urban Road Infrastructure on Supply Chain Network Vulnerability", Networks and Spatial Economics, vol. 18, no. 1, p. 85-113. 